\title{
How Artificial Intelligence Improves Agricultural Productivity and Sustainability: A Global Thematic Analysis
}

\author{
Vijaya Lakshmi \\ Université Laval \\ vijaya.1akshmi.1@ulaval.ca
}

\author{
Jacqueline Corbett \\ Université Laval \\ Jacqueline.Corbett@fsa.ulaval.ca
}

\begin{abstract}
Amidst the rising issues of food security and climate change, the agricultural sector has started deploying artificial intelligence (AI) in business operations. While many potential AI benefits are anticipated, a comprehensive understanding of the objectives motivating AI adoption and its impacts is lacking. This research attempts to fill this gap by exploring the key themes related to the use of AI in agriculture through the lens of dynamic capabilities. Using centering resonance analysis, we conduct text mining of news articles from 2014-2019 in the regions of Asia, Africa, Europe, and North America to identify how AI is addressing significant farming challenges. Globally, the results suggest that AI is primarily being applied to increase productivity and efficiency and secondarily to address labor shortages and environmental sustainability concerns. At regional level, the results reflect active AI adoption in North America and Europe with increasing efforts in Asia and Africa.
\end{abstract}

\section{Introduction}

Attaining the United Nations' Sustainable Development Goals of zero hunger by 2030 necessitates dramatic improvements in the agricultural sector. Moreover, disruptions due to unpredictable weather, global water scarcity, and greenhouse gas emissions during agricultural practices raise significant concerns [1]. The transition from conventional agricultural practices to a sustainable mode of growing food can lead to social and economic equity and a healthy environment [2]. Hence, accelerating agricultural productivity, while minimizing negative environmental impacts, is becoming a priority.

The integration of information technology (IT) within agriculture practices, also called agricultural information technology (AIT), has shown a remarkable progression in the last 20 years [3]. AIT can be used as a direct tool for improving agricultural productivity and as an indirect mechanism for empowering farmers to make informed decisions. The integration of IT within agriculture practices has led to the emergence of precision farming, a new approach that utilizes dataintensive techniques and tools to revolutionize agriculture [4]. A key element of precision farming is the application of artificial intelligence (AI) which harnesses a vast amount of data to inform farming decisions and value-added agriculture. The agricultural sector is implementing AI and machine learning (ML) applications to generate value by enhancing crop yields and addressing sustainability concerns [5].

Although precision farming is gaining popularity in practice, it has garnered limited interest from the IS research community. Early research has just started to study the adoption and diffusion of AIT [6] and precision agriculture [7]. AI and ML tools can provide actionable insights on weather, soil, and water conditions, ultimately leading farmers to make better decisions on planting, irrigation, and harvesting.

AI applications in agriculture are still nascent, so the motives and the challenges of technological innovation, as well as the impacts of AIT remain unexplored. These limitations are significant because the agricultural context differs from traditional manufacturing or business contexts where IS is typically studied. Both physical and natural conditions in the natural ecosystem make risk anticipation and decision-making processes more complex. Dynamic soil, weather, and atmospheric conditions, along with a myriad of biological interactions, play a critical role in determining the effect of technology on the desired outcomes. Motivated to build knowledge and improve the use of AI, this research analyzes the objectives and impacts of AI deployment in agriculture. We seek to understand the processes through which AI leads to improved agricultural outputs and addresses sustainability.

According to the resource-based view of organizations, productivity and performance are dependent on the availability of resources [8,9] and capabilities that direct these resources to attain 
profitability [10]. In particular, dynamic capabilities, the "abilities to reconfigure a firm's resources and routines, in a manner appropriate by its principal decision makers" [11], have helped to explain business change and sources of value creation in organizations. Applying this perspective, we suppose that agricultural firms can gain a competitive edge, enhance productivity, and reduce waste by exploiting, protecting, combining, and reconfiguring their resources and capabilities by deploying AI. Furthermore, the amalgamation of AIT and farmers' expertise and intuition about their agricultural lands can provide unique solutions to various problems related to land, water, and weather patterns encountered on farms [12].

This research investigates the question of how agricultural organizations globally and within the different geographical regions, use AI to create value, and address sustainability concerns. To answer this question, we conduct centering resonance analysis (CRA) of archived secondary data in the form of press releases and media reports of agricultural organizations that are actively deploying or plan to deploy AI. Our results suggest that, globally, AI is primarily applied to increase production and efficiency. During the process, technology also serves to address labor shortages and environmental issues. At a regional level, we find active AI deployment in North America and Europe with advancing efforts in Asia and Africa.

The paper is structured as follows. In the following section, we provide the relevant background of AIT, AI, and dynamic capabilities. Then, we present our methodology and results. This is followed by discussion, conclusion, and future research directions.

\section{Background}

\subsection{IT in the Agricultural Sector}

Agriculture is fundamental to human lives and plays a vital economic role in many countries. Enhancing productivity and maintaining quality is increasingly difficult amidst disruptive climate change and limited arable resources. Advanced IT, such as satellites, internet, mobile phones, and social media, are actively being deployed to address agricultural challenges. IT is expected to improve agricultural information and farming techniques to achieve better outputs, perhaps as much as $60 \%$ by 2030 [13].

Despite the anticipated improvements associated with AIT, its potential is not fully exploited. As compared to other sectors of the economy, the implementation of IT in agriculture, especially in rural areas, has been relatively slow and late [14] due to the economic circumstances and uncertainties associated with the return on investment [15]. Farming operations involve complex problems characterized by high uncertainty and multiple courses of actions [16]. Current IT innovations demonstrate the potential to provide farmers with adequate support in decision-making and other operations [7] in order to improve the efficiency, effectiveness, profitability, and productivity in agriculture. IT is increasingly being considered as a tool to achieve industrial transformations [17], agriculture being one of them. The contribution of IT to agriculture can be achieved through cost reduction, efficiency and improvements, and sustainability.

The extant literature on AIT focuses mainly on questions of adoption [18,19], which is attributed to factors such as the social influence of peers [6], farm size, location, farmer's level of education and age, the complementarity of technology, and access to information sources [20, 21, 22, 23]. Initial adoption decisions are reflected in the attitudes and behaviors of the adopters, while technology enthusiasts actively adopt technology, unwilling users maintain traditional farming practices. [24].

A second stream of research takes a design approach as AI techniques are integrated into agricultural practices to improve irrigation systems, crop and soil health, identification of crop diseases, weed control, and sustainable agricultural practices. Research has considered the design of applications, such as the Internet of things (IoT)-based irrigation systems [25], sensors to monitor soil moisture, $\mathrm{pH}$, humidity, temperature [26], and digital soil mapping utilizing AI technology to improve agricultural output and improve soil health [27]. The potential of AI to enhance productivity and combat challenges of weather unpredictability, crop loss, and economic stagnancy can revolutionize the current system of agricultural practices [28] and augment the economic benefits of agriculture.

\subsection{Dynamic Capabilities}

When assessing the business value of IS, a broader view of IT must be taken [29]. Research emphasizes the importance of IT capability, defined as the "firm's ability to mobilize and deploy IT-based resources in combination or co-present with other resources and capabilities" [29]. Nazir and Pinsonneault [30] assert that IS can enhance organizational agility by developing digital options, helping organizations to increase the pace of decision-making, facilitate communication, and respond quickly to changing conditions. Further, organizations' IT capability and the complementary effects of IT capability in conjunction with other coordination mechanisms are significant predictors of organizational performance [31]. The concept of IT capability relies on the assumption that, while the 
available resources can be easily replicated, a distinctive set of capabilities can operate to extend, modify, or create ordinary capabilities [32]. This set of capabilities, known as dynamic capabilities, focusses on understanding the processes behind the development of new resources and capabilities by organizations to support their strategies in a dynamic environment. Zollo and Winter [33] describe dynamic capabilities as learned and stable patterns of collective activity used by organizations to generate and modify their routine operations and achieve improved effectiveness.

The development of dynamic capabilities depends on a number of factors, including coordination and integration processes that support learning and reconfiguration of organizational processes, the organization-specific strategic position defined by asset structure and resource configurations, and the organization's history [34]. Dynamic capabilities are hard to develop and deploy, and therefore, are difficult for rivals to imitate. Once in place, dynamic capabilities allow organizations to shape a favorable surrounding business ecosystem and to achieve new forms of competitive advantage by creating new resources in congruence with the changing environment [35].

Within the agricultural context, AI could provide an edge to the existing practices and strategies to achieve productivity and sustainability goals. For example, dynamic capabilities in the form of AI can aid in sensing market price changes of agricultural products and provide specific directions with the planting and harvesting to avoid significant crop losses. Early disease detection and customized irrigation plans could improve overall productivity and effectiveness. AI-enabled weather forecasts provide precise, actionable insights regarding daily farm activities in real time. Such accurate information can allow preventive measures to reduce crop loss. As agricultural organizations adopt AI applications, they can build on the existing dynamic IT capabilities through learning practices over time.

\section{Methodology}

This research employs content analysis, a research approach that derives replicable and valid inferences through the interpretation of textual materials [36]. We used centering resonance analysis (CRA) to carry out this study as described below.

\subsection{Collection of data}

We chose to use secondary data for two reasons. First, for convenience and completeness, as the secondary data are publicly available across multiple regions to allow a basis for comparison. Second, the data provides the viewpoint of firms as well as other stakeholders, providing a more diversified perspective regarding the phenomenon of interest. The data in our study comprised English-language articles and reports published in the news media by agricultural organizations (farms, vendors, suppliers). The first step in the collection process was to determine appropriate keywords to allow us to retrieve the most relevant articles. AI is described as an umbrella construct, which includes several keywords, such as ML, deep learning, natural language processing, neural networks. As we base our study in the agricultural context and focus on precision farming to create value, we used the keywords: artificial intelligence, agriculture, precision farming, artificial intelligence AND agriculture, AI and agriculture and machine learning and agriculture to initiate the database search.

We searched the Factiva database, specifying the agriculture industry from January 1983 to March 2019. A region-specific search was conducted for North America, Europe, Asia, and Africa. Factiva is a global news database and has been used in various studies to conduct the data collection process [37]. To refine the results, we filtered our search to eliminate forestry, hunting, livestock, and fishing from within the farming criteria. We also restricted our search to exclude political, sports, market share, and financial news in order to concentrate on corporate and industrial announcements and press releases. Although articles mentioning AI application in agriculture date back to 1983, we observed that AI in the agricultural context gained prominence, in the beginning of 2015. Hence, we further restricted our date range from January 2014 to March 2019. This step resulted in 98 articles for Africa, 598 articles from Asia, 1965 articles for Europe, and 725 articles for North America. Once the articles were identified, we conducted an initial screening to ensure they met our inclusion criteria, namely, that the articles discussed the application of AI in agriculture. Articles that mentioned agriculture and AI but not in connection with each other were eliminated. Application of the inclusion criteria resulted in 54 articles for Africa, 317 articles for Asia, 454 articles for Europe, and 166 articles for North America. Our final sample consisted of 991 articles.

\subsection{Centering Resonance Analysis}

We analyzed the articles using CRA, a computerized text analysis tool [38]. CRA analyzes words and phrases together in significant ways to form a network, depicting their influence and inter-relationship. According to CRA analysis, a word in a text is considered to be more influential if it draws other words together in the text network that reflect some meaning [39]. Accordingly, 
an influence value is assigned to the most prominent word that draws the relationship between other words.

We used Crawdad Desktop 2.0 (Crawdad), consistent with other research [40]. Crawdad highlights the presence, influence, and resonance of code words [41] and creates network maps of the words for every sampled article. Influence values between 0 and 1 are assigned to words based on the principles of CRA, as explained above. An influence value of 0.01 is considered to be important, while a value above 0.05 is considered to be very important [42].

\subsection{Data Analysis}

We carried out the analysis into two parts. In the first part, the Crawdad parameters were set to identify the 250 most influential words that were common across the four geographical regions. The relevant articles were converted into readable texts and repetitive terms without meaning, such as organizations' names, were eliminated to avoid ambiguity in coding [42]. Each text file was converted into CRA file, and a network map and influential words for each CRA file were generated by Visualizer module.

The thematic structure of the data was assessed through exploratory factor analysis (EFA) utilizing principal component analysis and varimax rotation through the Sequencer module. The words with low factor loadings were removed [42]. Seven common themes comprised of 163 words in total, emerged from the analysis of the influence values of keywords and their relevance in the texts. These themes represent coherent groups of words and provide the foundation for latent coding. Latent coding permits researchers to search for implicit meanings in the text [43]. We performed latent coding to assess the suitability of words under each theme. If deemed appropriate, we recoded words from the original EFA loadings to a different theme, based on suitability and interpretability.

The second analysis focused on determining the relationship between the most influential words across the data sample. To determine the similarity and the differences between the influential words in the four regions, we first calculated the average influence score of the words that had influence value greater than or equal to 0.1 [44] for the four data samples. We limited the analysis to the words that appeared in at least 20 articles to avoid biases due to a word having a higher influence value but a lower appearance in texts [44]. Next, we looked for words that were similar across the four data sets. For example, agriculture emerged in all four data sets and had an influence value above 0.1 . The variance of a word's influence value across the texts within a dataset was used as an estimate of random variation. We then ran an ANOVA to test whether the average influence of a word was different depending on the dataset. Continuing with the previous example, ANOVA results for agriculture showed if the average influence of agriculture was significantly different across the four data sets. If significant $(p<0.05)$, we ran t-tests to determine where the significant difference was. We identified 52 identical or similar words across the four data sets for which we ran ANOVA.

\section{Results: Main Thematic Analysis}

Seven main themes were identified and organized according to elements of dynamic capabilities theory, as illustrated in Figure 1. First, there is a dynamic and changing environment surrounding organizations in the agricultural sector, which puts pressure on organizations' business strategies, capabilities, and objectives. Dynamic capabilities provide a mechanism for responding to this dynamic environment to achieve the objectives associated with business strategies. The seven themes and their associated words are illustrated in Table 1.

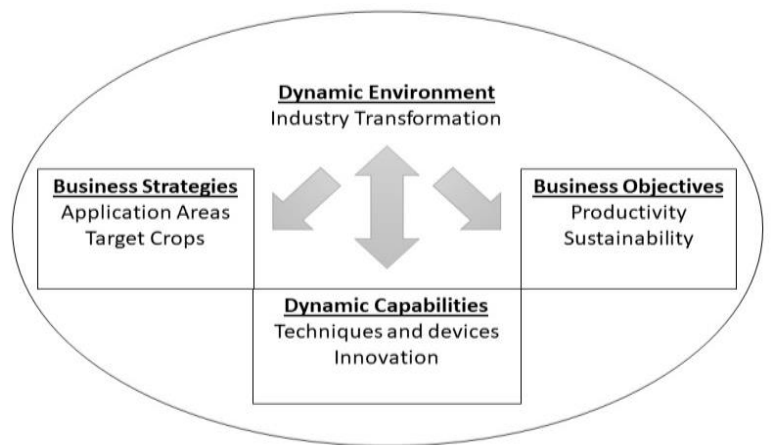

Figure 1: Emergent themes from CRA

\subsection{Industry Transformation}

The first theme speaks of industry transformation and the potential for significant shifts in the roles of the different players. As expected, the literature shows that a high degree of dynamism is expected within the agriculture sector, with new players assuming key roles and replacing incumbent players. Other players, such as venture capital firms, corporate venture funds, startups bring dynamism in the market and stakeholder network. While large agricultural organizations focus on setting up AI frameworks, startups deliver solutions all across the value chain, ranging from infrastructure, sensors, software algorithms that provide insights on the various streams of data across the farms. An increasing number of small IT startups are launching products and services, giving their counterparts strong business competition. Venture capital firms are keen on investing in agricultural companies as agriculture technology 
(agtech) gains popularity and momentum, as reflected in the following excerpt:

"Meanwhile, venture capital ... agritech start-up ... power to transform agriculture... send ripples through the entire sector." [45]

Table 1. Words associated with emergent themes

\begin{tabular}{|c|c|}
\hline $\begin{array}{l}\text { Industry } \\
\text { Transformation }\end{array}$ & $\begin{array}{l}\text { startup, investor, consultant, } \\
\text { trading, insurance, business, } \\
\text { market, retail, tax, } \\
\text { entrepreneurship, entrepreneur, } \\
\text { venture, way, management, service }\end{array}$ \\
\hline $\begin{array}{l}\text { Application } \\
\text { Areas }\end{array}$ & $\begin{array}{l}\text { irrigation, pesticide, soil, moisture, } \\
\text { nitrogen, picture, imagery, indoor, } \\
\text { analysis, area, system, control, } \\
\text { vertical, greenhouse, health, pivot, } \\
\text { weed, fertilizers, water, pest, stress, } \\
\text { spray, diseases, challenge }\end{array}$ \\
\hline Target Crops & $\begin{array}{l}\text { lettuce, cotton, grapes. vineyards, } \\
\text { tomatoes, oil, fruit, plant, fresh, } \\
\text { automatic, cloud, vegetables }\end{array}$ \\
\hline $\begin{array}{l}\text { Techniques } \\
\text { and Devices }\end{array}$ & $\begin{array}{l}\text { data, drones, sensors, computation, } \\
\text { computer, program, automation, } \\
\text { software, broadband, equipment, } \\
\text { camera, smart, processing, deep } \\
\text { learning, precision, ML, vehicles, } \\
\text { internet, app, iot, digital, network, } \\
\text { web, display, mobile, engineering, } \\
\text { surveillance, tractor, unmanned, } \\
\text { tech, automatic, cloud, pattern, } \\
\text { algorithm, technique, tool, } \\
\text { autonomous, model, precise }\end{array}$ \\
\hline Innovation & $\begin{array}{l}\text { r\&d, science, technology, } \\
\text { government, investments, } \\
\text { scientists, copyright, invention, } \\
\text { wave, people, participation, exhibit, } \\
\text { aim, agtech, patent, industry, } \\
\text { funding, leader, report, career, } \\
\text { developer, project, conference, } \\
\text { solution, platform }\end{array}$ \\
\hline Productivity & $\begin{array}{l}\text { yield, harvest, cost, crop, grain, } \\
\text { produce, vast, organic, percent, } \\
\text { food, grower, farming, farmers, } \\
\text { field, acre, decision, } \\
\text { transformation, workers, labor, } \\
\text { momentum, farmers, farm, } \\
\text { challenges, power, efficiency, risk, } \\
\text { economic, economy, competition, } \\
\text { future, error, information, price, } \\
\text { firm, time, operation, trade }\end{array}$ \\
\hline Sustainability & $\begin{array}{l}\text { climate, weather, energy, } \\
\text { environment, condition, } \\
\text { sustainable, chemical, green, } \\
\text { responsible, gas }\end{array}$ \\
\hline
\end{tabular}

\subsection{Application Areas}

The second and third themes relate to the business strategies and operations most affected by AI. The second theme reveals the core areas of application of AI in agriculture. The relevant influential words in this theme show that AI is being applied in the greenhouse, vertical, and indoor farming to address persistent problems that impact productivity, such as less irrigation, decreasing soil quality and crop diseases.

Deep learning applications monitor crop and soil health by detecting nutritional deficiencies and potential defects in the soil. Software algorithms correlate specific foliage patterns with nutritional and soil defects, plant pests, and other diseases. ML is applied in predicting weather patterns and evaluation of farms for diseases, pests, and weed. One of the most prevalent applications of AI relates to scheduled and efficient irrigation systems. ML algorithms analyze the soil moisture and provide adequate irrigation strategies depending on the crop, soil types, and environmental conditions. These systems, in turn, help preserve water and increase output. The decision-enhancing capability of AI is highlighted in the following excerpt,

"Utilizing tools... soil moisture monitoring, nearreal-time, and ...use, quantitative precipitation forecasting ... decisions of crop irrigation." [46]

\subsection{Target Crops}

The third theme relates to the crops most targeted by AI applications. The initial application of AI seems to be in growing specific crops. Lettuce farming is being carried out in indoor vertical farming set up to produce higher yields than in normal conditions. Fruit and vegetable also constitute major focus crop categories. The importance of these crops relates in part to customer demand for fresh fruits and produce. Thus, AI can offer visibility concerning the easiest and best approaches to fill this demand. The results demonstrate the application of $\mathrm{AI}$ techniques to monitor the growth of crops that are regular and in high demand and those that require heavy and regular irrigation such as cotton and grapevines. The objective is to deploy AI in growing crops that involve larger land mass to enable efficient, costeffective, less labor-intensive farming practices.

\subsection{Techniques and Devices}

The fourth theme relates to specific techniques and devices being used, which form part of the set of dynamic capabilities. AI is being applied through drones, ML, and deep learning algorithms. Such techniques and devices can transform farm management 
through accessibility to explicit information and informed decisions that were not previously possible. Analysis of agricultural data from drones and sensors can provide useful information and guidance regarding the irrigation, pests, and crop diseases and support the precise application of fertilizers in real time. Wireless communications technologies provide the opportunity to access farm data from a distance, enabling farmers to make decisions regarding harvest, farm conditions, and ways to bring their products to market. Automated tractor, harvesters, fruit-picking robots replace human labor in routine tasks leading to the efficient, precise, and cost-effective mode of farming, as illustrated in the following excerpt:

"We have a real advantage for spot-spraying. The drone system limits the use of labor, ... locations traditional sprayers can't reach...." [47]

\subsection{Innovation}

The fifth theme relates to innovation. Our analysis suggests that technological innovation associated with $\mathrm{AI}$ is a response to pressures for industry transformation. Governments are actively looking to invest in AI to increase agricultural profitability and productivity. Apart from increasing productivity, AIT may also provide social benefits and security. Words such as invention, copyright, patent, and science point towards the efforts to increase the research and development for responsible innovations. Such innovative research environment, capable of revolutionizing the agricultural sector, is encouraged through governments and investments. With agriculture being essential for continued human existence, there is a pressing need to move away from inefficient, traditional practices and innovate to improve farming practices and decisionmaking. This idea is reflected in the following excerpt:

"Digital innovation ... to improve food safety, reduce the environmental impacts of..., and create good middle-class jobs." [48].

\subsection{Productivity}

The sixth emergent theme relates to productivity. Farmers are continually looking to improve efficiency and profitability through cost reduction and obtaining better prices for their produce. AI provides the platform for better farm management. Historically, farming decisions were derived through farmers' knowledge and experience, but now AI enables a mix of human and computer-derived decisions. Applications of AI is changing the mode of operations and management of farms, the key areas of change being real-time forecasting and reinvention of business processes. The operational value within the agricultural sector is created through a productivity boost, as evident from the keywords such as yield, harvest, grower, produce. Algorithms decrease the dependency on manual predictions, mitigate risks, reduce error, and facilitate more accurate yield predictions, leading to significant efficiency and savings for the farmers. AI provides predictive insights into the potential future outcomes, such as predictive yield models, allowing for real-time operational decisions and game-changing business models, as this excerpt illustrates:

"SunSelect, a California greenhouse...after Motorleaf's algorithms doubled the accuracy of its weekly yield projection, resulting in significant savings...." [49]

\subsection{Sustainability}

The final theme relates to sustainability, that is, increasing productivity without harming the environments and, if possible, also generating social and environmental benefits. Through the precise application of fertilizers, pesticides, and systemized irrigation, AI allows for the reduction of environmental impacts. Reduced application of chemicals, adequate irrigation in the farm areas that require more water or specific to crops can reduce the use of water and initiate a sustainable mode of agricultural practices as the extract below explains:

"Precision agriculture is ... reducing the environmental footprint while increasing production and advances such as... helping to make greenhouse production more efficient." [50]

In terms of social sustainability, however, there are doubts regarding the replacement of farmers' knowledge by algorithms and the disruption that technology will bring into the agricultural sector. Application of driverless tractor and robots increase the risk of job loss and social inequality. While AI has the potential to expand and increase the agriculture sector, it could exacerbate the economic divide in society.

\section{Results: Regional Comparative}

The analysis of the 52 common and most influential words revealed 23 words whose influence varied across the four regions (Table 2). The word agriculture had a higher influence score (0.070) in the African context, followed by Asia (0.053), North America (0.039) and Europe (0.031). The t-tests for the word agriculture (Table 3) suggested significant differences between the four different regions. The word agriculture is more prominent in the trade press from Asia as compared to Europe, given Asia is a developing and agriculturalcentric economy. Hence the focus is more on 
safeguarding the traditional occupation and protecting the industry. In contrast, the word precision had more influence value in the context of Europe (0.042) as compared to Asia (0.015) and North America (0.012), suggesting a more active use of precision agriculture in Europe. In Asia, as compared to other regions, AI provides a platform for researching (0.031) and finding solutions (0.015) to the problems in agriculture.

Due to space limitations, the influence scores for each word per region are not provided. In what follows next, we provide a synthesis of the use of AI in agriculture in each region as reflected by the top influential words in that region.

\section{Table 2. Top influential and similar words}

\begin{tabular}{|l|l|}
\hline $\begin{array}{l}\text { The 52 most } \\
\text { influential } \\
\text { and similar } \\
\text { words across } \\
\text { the four data } \\
\text { sets }\end{array}$ & $\begin{array}{l}\text { agriculture, agricultural, ai, } \\
\text { application, area, big, business, } \\
\text { event, farm, farmer, farming, field, } \\
\text { food, global, good, government, } \\
\text { industry, information, innovation, } \\
\text { land, machine, market, new, } \\
\text { platform, precision, product, } \\
\text { production, project, report, research, } \\
\text { robot, sector, sensor, soil, software, } \\
\text { solution, state, start-up, system, } \\
\text { technology, time, tractor, university, } \\
\text { vegetable, water, way, world, year }\end{array}$ \\
\hline Significant 23 words per region \\
\hline North & $\begin{array}{l}\text { ai, big, business, data, startup, time, } \\
\text { America }\end{array}$ \\
\hline Europe & $\begin{array}{l}\text { event, farming, new, precision, } \\
\text { robot, soil, system, tractor }\end{array}$ \\
\hline Asia & $\begin{array}{l}\text { agriculture, state, solution, research, } \\
\text { vegetable }\end{array}$ \\
\hline Africa & platform, report \\
\hline
\end{tabular}

In North America, $A I$ emerged as a highly influential word as compared to the other three regions, suggesting that AI applications are more pronounced in North America, creating different ways to expand and change agriculture. Higher influence values of big and data point towards utilization of data-intensive techniques and data exploitation to create value in agriculture. Such techniques reduce routine tasks enabling farmers to spend their time focusing on the overall operation of their business. This is consistent with the emergence of a startup as highly influential in the North American context. The focus on AI and data applications with a business context provides fertile ground for the emergence of agtech startups.

In contrast to North America, the influence values for the words robots and soil were high in the European context. This suggests perhaps a more focused implementation of AI. European farms are deploying robots to make farming efficient and cost-effective with attention to monitoring soil conditions through ML applications, to enhance output and profitability. Precision farming is gaining prominence as a new mode of sustainable farming. Also, numerous events are being organized by vendors to promote new AI-enriched products such as automated tractors and robots.

Contrasting with North America and Europe, AI endeavors are in the infancy stage in the context of developing economies, i.e., Asia, and Africa. The influential keywords in these regions suggest that research activities promoting awareness and development of AI and agriculture are more prominent in Asia. The results point toward the increasing deployment of AI in the Asian context as the solution to the major agriculture problems like low production and crop loss. In the African context, AI is considered as a platform to achieve economic pursuits in agriculture research, and studies are being carried that report the need and significance of AI implementation in the African agriculture sector.

Table 3. Statistical tests of the influence of agriculture across the four data sets

\begin{tabular}{|c|c|c|c|c|c|c|}
\hline \multicolumn{7}{|c|}{ Cases Homogeneity Correction Sum of Squares } \\
\hline$\overline{\mathrm{ID}}$ & None & 0.140 & 3.000 & 0.047 & 7.691 & $<.0010 .023$ \\
\hline ID & Brown-Forsythe & 0.140 & 3.000 & 0.047 & 8.354 & $<.0010 .023$ \\
\hline ID & Welch & 0.140 & 3.000 & 0.047 & 7.604 & $<.0010 .023$ \\
\hline Residua & 1 None & 5.967 & 986.000 & 0.006 & & \\
\hline Residua & Brown-Forsythe & 5.967 & 414.041 & 0.014 & & \\
\hline Residua & 1 Welch & 5.967 & 221.116 & 0.027 & & \\
\hline \multicolumn{7}{|c|}{ Note. Type III Sum of Squares } \\
\hline \multicolumn{7}{|c|}{ Post Hoc Comparisons - ID } \\
\hline & Mean Difference & & SE & $\mathbf{t}$ & & $\mathbf{p}_{\text {tukex }}$ \\
\hline \multirow[t]{3}{*}{1} & & 0.021 & 0.01 & & .790 & 0.265 \\
\hline & & 0.042 & 0.01 & & .723 & $<.001$ \\
\hline & & 0.034 & 0.01 & & .781 & 0.026 \\
\hline \multirow{2}{*}{2} & & 0.021 & 0.00 & & .713 & $<.001$ \\
\hline & & 0.013 & 0.00 & & .794 & 0.263 \\
\hline 34 & & -0.008 & 0.00 & & .118 & 0.665 \\
\hline
\end{tabular}

\section{Discussion}

This research was motivated to build knowledge around AIT as well as to improve the use of AI by analyzing the objectives and impacts of AI deployment in the agricultural sector through the lens of dynamic capabilities. As the theory suggests, organizations must develop new capabilities in order to be able to adapt rapidly to changing conditions in order to stay competitive. The dynamic environment that drive the need for agricultural transformation is multidimensional. First, it includes the natural environment wherein climate change is creating unpredictable weather patterns and natural resource scarcity that threatens sustainability. Second, the 
competitive market environment is changing, and farm organizations must continually strive to reduce costs and increase productivity. The third dimension is the technological environment, where AI is both a response to and a cause of industry transformation. In the pursuit of agricultural transformation, AIT is mutually evolving, becoming a core driver of agricultural performance, productivity, efficiency, and sustainability. Transformative technologies, such as AI and precision farming, are critical in meeting the target of food security and environmental concerns. As our study suggests, this transformation is in its early stages, with AI initially being deployed to address core problems related to irrigation, crop diseases, weed control, and soil health.

The rapid industry transformations brought in due to technological innovations leads organizations to modify, generate, and extend their operational capabilities to improve efficiency. That being said, the primary goal of achieving the benefits of AI is heavily reliant on processes utilized by organizations to effectively mobilize their technical resources. This study suggests the benefits of AI resources in the form of different tools and techniques such as sensors, drones, robots, can be enhanced through the development of capabilities that direct these resources effectively. In this respect, innovation capabilities and strong leadership are prerequisites for organizational success in this dynamic environment. Innovation capabilities generated through constant learning processes within an organization, open avenues to enhanced performance and success. Also, complementary investments, such as adequate training and development of appropriate skill sets [51] are required to harness the benefits of AI. Hence, farm organizations will need to educate and train their employees to achieve the maximum benefits of AI.

Coupling the technical capabilities of AI with other organizational capabilities will result in a distinctive set of resources and dynamic capabilities with two main areas of benefit: operational and environmental. Our analysis highlights the fact that farmers and other agricultural organizations are adopting AI to cut labor costs or to replace labor needs. Labor shortages and efficiency demand influence farmers' interest in adopting AI. Automated agricultural vehicles and robots serve the same task with more precision in less time, reducing the cost and increasing the quality of practices. However, given the challenges associated with the substantial cost of initial adoption and installment of AIT, the expected benefits may go unrealized. The environmental value creation through AI deployment derives from precise applications of fertilizers, weedicides, and pesticides. Such applications not only reduce the harmful chemicals in the food chain but also shrink the carbon footprint of operations, thus creating value in terms of sustainability.

As the growth of AI implementation in agriculture continues, an interesting and important question arises regarding the roles of different actors. Given the specialized skill required to leverage AI, one may wonder whether it is possible for farmers to develop these skills in-house. Our analysis suggests that not all farm organizations will be required to develop the technology and algorithms. Instead, they may be able to rent or acquire a few AI services, which would be sufficient to serve the long term of objectives of the organization. Agricultural startups are emerging with innovative solutions, adding to the competitiveness of the sector. However, farmers must be able to understand the applicability, benefits, and future of such solutions before deployment. Farmers feel pride in their traditional occupation and are reluctant to change their farming practices unless the technology promises higher returns on investments and is user-friendly.

Finally, similar to other sectors, the ethics of AI will require some thought in the agriculture sector as well. The concerns over data privacy, transparency, and unintended consequences of technology in the form of the regional digital divide, job loss, economic divide, and the dehumanizing impact of IT require significant attention. These are questions that IS researchers, working in multidisciplinary collaboration with agricultural researchers and practitioners could and should tackle in the coming years.

\section{Conclusion}

This paper makes three contributions to the IS literature. First, the study contributes to the literature on Green IS by highlighting the role of AI in addressing the sustainability concerns in agriculture. Second, we add to the dynamic capabilities literature by providing insights into the types of digitally based and organizational capabilities that might be required to gain value from AI in the agricultural context, with a view to mitigating the modern productivity paradox. Third, the research shines a light on a sector that has traditionally been neglected in IS research. Agriculture is critical in food security, and hence, IT can create interesting opportunities to combat existing food problems and environmental challenges. Moreover, understanding AI adoption and deployment in the agriculture sector may help us to inform AI solutions in other similar sectors.

In terms of limitations, this research should be considered only as a first step in the examination of AI in agriculture. Secondary data in the form of news articles have biases and limitations in providing in-depth insights on a phenomenon. In addition, our sample included only English-language articles that may not 
reflect a complete set of issues at the local levels. Therefore, we suggest continuing research that investigates the adoption and deployment of AI applications in agriculture through primary data in the form of interviews, case studies and surveys. In addition, productivity and sustainability performance associated through AI may be better evaluated through longitudinal data and studies.

To conclude, the application of AI in agriculture is still in its infancy, but there is much potential to develop this technology to address critical issues related to crop productivity while also respecting and addressing serious environmental concerns.

\section{References}

[1] EPA, "Sources of Greenhouse gases," https://www.epa.gov/ghgemissions/sources-greenhouse-gasemissions, April, 2019[accessed 2019-05-09].

[2] G. Feenstra, "Agricultural Sustainability Institute," https://asi.ucdavis.edu/programs/ucsarep/about/what-issustainable-agriculture, 2019 [accessed 2019-05-04].

[3] Y. Wang, L. Jin, and H. Mao, "Farmer cooperatives intention to adopt agricultural information technologymediating effects of attitude," Information Systems Frontiers, 2019, pp.1-16.

[4] S. Giesler, "Digitization in agriculture- from precision farming to farming 4.0",https://www.biooekonomiebw.de/en/articles/dossiers/digitisation-in-agriculture-fromprecision-farming-to-farming-40/. 2018 [accessed 2019-0503].

[5] A. Koeleman, "We are only at the beginning of digital farming,"https://www.futurefarming.com/Smartfarmers/Articles/2018/10/We-are-only-at-the-beginning-ofdigital-farming-343837E/, Oct 2018 [accessed 2019-05-09].

[6] G. Fox, J. Mooney, and P. Rosati, "Towards an understanding of farmers mobile technology adoption: a comparison of adoption and continuance intentions," AMCIS, New Orleans, 2018.

[7] B.A. Aubert, A. Schroeder, and J. Grimaudo, "IT as enabler of sustainable farming: an empirical analysis of farmers adoption decision of precision agriculture technology," Decision Support System, vol. 54, 2012, pp. 510512 .

[8] E. Brynjolfsson, and L.M. Hitt, "Paradox Lost? Firm-Level Evidence of High Returns to the Information Systems Spending," Management Science, vol. 42, no. 4, 1996, pp. 541-558.

[9] M.C. Anderson, "Value implications of investments in information technology," Management Science, vol. 52, no.9, 2006, pp.1359-1376.
[10] J. Barney, "Firm resources and sustained competitive advantage," Journal of Management, vol.17, 1991, pp. 99-120.

[11] S.A. Zahra, H.J. Sapienza, and P. Davidsson, "Entrepreneurship and dynamic capabilities: A review, model and research agenda," Journal of Management Studies, vol.43, 2006, pp.917-955.

[12] Farmbeats, "Democratizing AI for farmers around the world," https://www.microsoft.com/en-us/garage/wall-offame/farmbeats/ Microsoft, 2019 [accessed 2019-05-09].

[13] D. Newman, "Top six digital transformation trends in agriculture,",https://www.forbes.com/sites/danielnewman/20 18/05/14/top-six-digital-transformation-trends-inagriculture/\#55cfd2fded2e, 2019 [accessed 2019-05-09].

[14] S. Milovanovic, "The role and potential of information technology in agricultural improvement," Economics of Agriculture, vol.61, no.2, 2014, pp.471-485.

[15] P.R. Tozer, "Uncertainty and investment in precision agriculture - is it worth the money?" Agricultural Systems, vol.100, 2009, pp.80-87.

[16] B. Recio, F. Rubio, and J.A. Criado, "A decision support system for farm planning using AgriSupport II." Decision Support Systems, vol. 36, no.2,2003, pp.189-203.

[17] R. Heeks, "ICT4D 2016: New Priorities for ICT4D Policy, Practice, and WSIS in a Post-2015 World," Developing Informatics Working Paper Series, No. 59/2014, Manchester, UK: Institute for Development Policy and Management, 2014.

[18] B. Dey, D. Newman, and R. Prendergast, "Analysing appropriation and usability in social and occupational lives-an investigation of Bangladeshi farmers' use of mobile telephony." Information Technology and People, vol.24, no.1, 2011, pp.46-63.

[19] A. Ali, D.B. Rahut, and B. Behera, "Factors influencing farmers' adoption of energy-based water pumps and impacts on crop productivity and household income in Pakistan." Renewable \& Sustainable Energy Reviews, vol.54, no.2, 2016, pp.48-57.

[20] H. Auernhammer, "Precision farming - The environmental challenge," Computers and Electronics in Agriculture, vol.30, 2001, pp. 31-43.

[21] S.G. Daberkow, and W.D. McBride, "Farm and Operator Characteristics Affecting the Awareness and Adoption of Precision Agriculture Technologies in the US," Precision Agriculture, vol.4, no.2, 2003, pp.163-177.

[22] S. Fountas, S. Blackmore, D. Ess, S. Hawkins, G. Blumhoff, J. Lowenberg-Deboer, et al. "Farmer Experience with Precision Agriculture in Denmark and the US Eastern Corn Belt," Precision Agriculture, vol. 6, 2005, pp. 121-41. 
[23] N.R. Kitchen, C.J. Snyder, D.W. Franzen, W.J. Wiebold, "Educational needs of precision agriculture," Precision Agriculture, vol.3, 2002, pp.341-351.

[24]Cavallo, E., E. Ferrari, L. Bollani, and M. Coccia, "Attitudes and Behaviour of Adopters of Technological Innovations in Agricultural Tractors: A Case Study in Italian Agricultural System.” Agricultural Systems, vol.130, 2014a, pp.44-54.

[25] J. Gutierrez, J.F. Villa-Medina, A. Nieto-Garibay, and M. A. Porta-Gandara, "Automated irrigation system using a wireless sensor network and gprs module," Instrumentation and Measurement, IEEE Transactions, vol. 63, no. 1, 2014, pp.166- 176.

[26] C. Cambra, S. Sendra, J. Lloret, and L. Parra, "Ad hoc Network for Emergency Rescue System based on Unmanned Aerial Vehicles," Network Protocols and Algorithms, vol.7, no 4, 2015, pp. 72-89.

[27] R. Dong, Martyenko, "A, Guest editorial: Robotics and automation in agriculture," International Journal of robotics and automation, 2018

[28] Irimia, M, "Five ways agriculture could benefit from artificial intelligence,” IBM, 2016.

[29] A.S. Bharadwaj, "A resource-based perspective on information technology capability and firm performance: an empirical investigation,” MIS Quarterly, vol.24, no. 1, 2000, pp.169-196.

[30] S. Nazir, and A. Pinsonneault, "IT and firm agility: an electronic integration perspective," Journal of the Association for Information Systems, vol.13, no.3, 2012, pp.150-171.

[31] S. Bharadwaj, A. Bharadwaj, and E. Bendoly, "The performance effects of complementarities between information systems, marketing, manufacturing, and supply chain processes," Information Systems Research, vol. 18, no. 4, 2007, pp. 437-53.

[32] S.G. Winter, "Understanding dynamic capabilities." Strategic Management Journal, vol.24, 2003, pp. 991-996.

[33] M. Zollo, and S. G. Winter, "Deliberate learning and the evolution of dynamic capabilities," Organization Science, vol. 13 , no. 3, 2002, pp.339-353.

[34] D. Teece, G. Pisano, and A. Shuen,"Dynamic capabilities and strategic management", Strategic Management Journal, vol. 18, no. 7, 1997, pp.509-533.

[35] G. Pan, S.L. Pan, and C.Y. Lim, "Examining how firms leverage IT to achieve firm productivity: RBV and dynamic capabilities perspectives," Information and Management, vol.52, no.4, 2015, pp. 401-412.
[36] S. Stemler, "An overview of content analysis," Practical assessment, research \& evaluation, vol.7, no.17, 2001, pp. 137-146.

[37] F. Weingarten, C.K.Y. Lo and J.Y.K. Lam, "How does Sustainability Leadership Affect Firm Performance, The Choices Associated with Appointing a Chief officer of corporate social responsibility," Journal of Business Ethics, vol.140, 2017, pp. 477-493.

[38] S.R. Corman, T. Kuhn, R.D. McPhee, and K.J. Dooley, "Studying Complex Discursive Systems, "Human communication research, vol.28, no.2, 2002, pp.157-206.

[39] H.E. Canary, and M.M. Jennings, "Principal and influence in codes of ethics: A centering resonance analysis comparing pre-and post -Sarbanes-Oxley Codes of ethics.," Journal of Business Ethics, vol. 80, no.2, 2008, pp. 263-278.

[40] S.A. Augustin-Behravesh, and K. Dooley, "Differentiating Sustainably": Relating organizational culture to corporate sustainability strategies," AOM, Chicago,2018.

[41] S. Corman, and K. Dooley, "Crawdad text analysis system 2.0". Chandler, AZ: Crawdad Technologies, LLC, 2006.

[42] W.L. Tate, L.M. Ellram., and J.F. N Kirchoff, "Corporate social responsibility reports: a thematic analysis related to supply chain management," Journal of Supply Chain Management, vol. 46, 2010, pp. 19-44.

[43] W.L. Neuman, Social research methods (4th ed.), Allyn and Bacon, London, 2000.

[44] C.L. Rossetti, and K.J. Dooley, "Job types in the supply chain management profession", Journal of Supply Chain Management, vol.46, 2010, pp. 40-56.

[45] E. Terazono, https://www.ft.com/content/ee6fb294-edc311e8-8180-9cf212677a57, 2018[ accessed 2019-5-2].

[46] K. Ledbetter, https://tinyurl.com/y23znfdv [accessed 2019-5-2]

[47] R. Swoboda, https://tinyurl.com/y57xmpug [accessed 2019-5-9]

[48] Cision, https://tinyurl.com/y3gnq4v2 [accessed 2019-59].

[49] R. Marowits, https://tinyurl.com/y4fdr9pc [ accessed 2019-5-1]

[50] A. Liris, and G, Sawyer, https://tinyurl.com/y9o2pbyb [ accessed 2019-5-13]

[51] E. Brynjolfsson, D. Rock, and C. Syverson, "Artificial Intelligence and the Modern Productivity Paradox: A Class of Expectations and Statistics," NBER Working Paper, 2017. 